\title{
Research
}

\section{Help needed in medication self-management for people with visual impairment:}

\author{
case-control study
}

\begin{abstract}
\section{Background}

Visual impairment (VI) is rising in prevalence and contributing to increasing morbidity, particularly among older people. Understanding patients' problems is fundamental to achieving optimal health outcomes but little is known about how VI impacts on self-management of medication.

\section{Aim}

To compare issues relating to medication selfmanagement between older people with and without VI.

\section{Design and setting}

Case-control study with participants aged $\geq 65$ years, prescribed at least two long-term ora medications daily, living within the community.

\section{Method}

The study recruited 156 patients with VI lbest corrected visual acuity [BCVA] 6/18 to 3/60) at low-vision clinics; community optometrists identified 158 controls (BCVA 6/9 or better). Researchers visited participants in their homes, administered two validated questionnaires to assess medication adherence (Morisky; Medication Adherence Report Scale [MARS]), and asked questions about medication selfmanagement, beliefs, and support.

\section{Results}

Approximately half of the participants in both groups reported perfect adherence on both questionnaires (52.5\% Morisky; 43.3\%, MARS). Despite using optical aids, few (3\%) with VI could read medication information clearly; $24 \%$ had difficulty distinguishing different tablets. More people with VI (29\%) than controls (13\%) lodds ratio $[\mathrm{OR}]=2.8 ; 95 \%$ confidence interval $[\mathrm{Cl}]=1.6$ to 5.0 ) needed help managing their medication, from friends (19\% versus $10 \%$ ) or pharmacists ( $10 \%$ versus $2.5 \%$; OR $=4.4,95 \% \mathrm{Cl}=1.4$ to 13.5 ) more received social service support $(\mathrm{OR}=7.1$ $95 \% \mathrm{Cl}=3.9$ to 12.9 .
\end{abstract}

\section{Conclusion}

Compared to their peers without VI, older people with $\mathrm{Vl}$ are more than twice as likely to need help in managing medication. In clinical practice in primary care, patients' needs for practical support in taking prescribed treatment must be recognised. Strategies for effective medication self-management should be explored.

\section{Keywords}

medication adherence; older people; prescriptions; primary care; visually impaired persons.

\section{INTRODUCTION}

Visual impairment (VI) constitutes a major public health burden. ${ }^{1}$ Its prevalence is rising and is greater among older people, predisposing to difficulty in practical daily living activities, ${ }^{2}$ reduced quality of life, ${ }^{3}$ and increased morbidity, including falls, ${ }^{4}$ depression, ${ }^{5}$ suicide, ${ }^{6}$ and cognitive decline.? Optimal health outcomes are associated with people's ability to self-manage illness. ${ }^{8}$ Many older people require long-term complex therapies for the management of multiple chronic diseases: medication adherence is of key importance in optimising the overall effectiveness of their health care. 9.10 Those with reduced visual acuity may be at particular risk of medication nonadherence, with potential adverse consequences for their health, but little is known about the impact of visual impairment on medication selfmanagement. Medication non-adherence in older people has not been well described. ${ }^{10}$

The use of prescription drugs is rising in both the US and the UK: over $90 \%$ of those aged $>65$ years take at least one prescription medication long term and

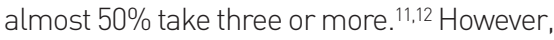
recent estimates indicate that, in the

RM McCann, PhD, research fellow, Department of Ophthalmology, Royal Group of Hospitals Belfast and Centre for Public Health Research, Queen's University, Belfast. AJ Jackson, BSc(Hons), PhD MCOptom, FAAO, FBCLA; head of optometry, Belfast Health and Social Care Trust; assistant director, Integrated Care Health and Social Care Board; head of clinical services, National Vision Research Institute, Australian College of Optometry, Melbourne, Australia.

MR Stevenson, BSc, FSS, senior lecturer in medical statistics, Centre for Public Health Research; M Dempster, PhD, CPsychol, CStat, AFBPsS, FHEA, senior lecturer, School of Psychology; JC McElnay, PhD, FPSNI, FCCP, professor of pharmacy practice, School of Pharmacy, Queen's University, Belfast. ME Cupples, MD, FRCGP, professor of general practice; clinical lead, Northern Ireland Clinical developed world, only approximately $50 \%$ of patients with chronic disease adhere to treatment recommendations. ${ }^{13}$ Various predictors of adherence have been identified, including the complexity and costs of treatment, characteristics of the illness, and personal factors, ${ }^{13}$ such as physical dependency, ${ }^{14}$ concerns about medicines, 9,15 and social support. ${ }^{15}$ GPs are the key coordinators in prescribing in primary care. ${ }^{16}$ Their role in understanding patients' problems and ensuring that management plans are appropriate, is fundamental in promoting medication adherence and optimising outcomes. The extent to which individuals with $\mathrm{VI}$, compared to their peers with normal sight, require or receive support in managing medication has not been reported but has potentially important implications for prescribing in primary care. Therefore, this study aimed to compare levels of medication adherence between older people with and without $\mathrm{VI}$, and to examine issues related to their management of their medication.

\section{METHOD}

\section{Participant recruitment}

Individuals aged $\geq 65$ years, who attended

Research Network (Primary Care), Centre for Public Health Research and Department of General Practice and Primary Care, Queen's University Belfast, and UKCRC Centre of Excellence for Public Health Research (Northern Ireland).

\section{Address for correspondence}

Margaret Cupples, Department of General Practice and Primary Care, Queen's University Belfast, 1 Dunluce Avenue, Belfast, BT9 7HR.

E-mail: m.cupples@qub.ac.uk

Submitted: 11 January 2012; Editor's response: 14 March 2012; final acceptance: 22 March 2012. (CBritish Journal of General Practice This is the full-length article (published online $30 \mathrm{Jul}$ 2012) of an abridged version published in print. Cite this article as: Br J Gen Pract 2012; DOI: 10.3399/bjgp12X653570. 


\section{How this fits in}

Visual impairment is an increasing health problem, particularly among older people, and contributes to comorbidities that require long-term medication in primary care. Little is known about the impact of visual impairment on medication adherence or self-management. This study shows that almost $30 \%$ of older people with defined visual impairment need help in managing their medication, despite using optical aids; they are more than twice as likely as their peers without impaired vision to receive help from friends or statutory services. To ensure optimal health outcomes, clinicians must ask about problems with vision and check that appropriate support is available for individuals to take their medication as prescribed.

the regional multidisciplinary low-vision clinic at the Royal Victoria Hospital, Belfast, and peripheral outreach clinics in Northern Ireland, were identified. They were sent information about the study, in large print, with a routine clinic appointment, and offered the information in audio format. At the clinic, the optometrist invited participation from those taking two or more different long-term oral medications daily, living within the community, not receiving daily medical or nursing care, and not participating in other research. For those who agreed, the optometrist recorded post refraction best corrected distance and near visual acuities (BCVA) using Bailey Lovie distance, and near-text reading charts. ${ }^{17}$ Visual impairment was defined by the World Health Organization (WHO) classification BCVA $<6 / 18$ and $>3 / 60^{18}-$ and those with BCVA outside these limits were excluded. Thus, all had some usable vision and were given optical aids, including spectacles.

Primary care community optometrists recruited the control (C) group. They invited people aged $\geq 65$ years to participate if they were taking two or more long-term oral medications daily, living in the same localities as those recruited with VI lto ensure availability of similar services), not requiring daily medical or nursing care and, had a BCVA of 6/9 or better. VA was measured using standardised optometry instrumentation and the same protocol as in the low-vision clinics. Anonymous data about those who declined to participate were recorded.

\section{Data collection}

All participants were visited at home (April
2007 to February 2010), where cognitive function was assessed (12-item Clifton Assessment Schedule) (CAS) ${ }^{19}$ and a researcher administered a bespoke questionnaire to gather information about living arrangements, educational status, falls, social support, and use of health and social care services. A measure of socioeconomic status was derived from participants' postcodes (Multiple Deprivation Measure [MDM]]: ${ }^{20}$ possible scores range from 1 to 890 and lower scores indicate greater deprivation.

Self-reported medication adherence was assessed by two validated measures, the Medication Adherence Report Scale (MARS; five questions about non-adherence behaviours, responses to each on a fivepoint scale) ${ }^{21}$ and Morisky Scale 22 (four questions, yes/no responses). Beliefs about medication were examined using questions based on constructs linked to the health belief model ${ }^{23}$ and theory of planned behaviour. ${ }^{24}$ Quality of life (QoL) was assessed using validated generic (Short Form 12 [SF-12], ${ }^{25}$ EuroQol 5D [EQ-5D] ${ }^{26}$ ) and vision-specific (Daily Living Tasks associated with Vision [DLTV]) ${ }^{27}$ questionnaires. Questions were asked about the use of optical aids, handling medications, and reading medicationrelated information.

With participants' consent, for a randomly selected $10 \%$ sample, prescribing data were collected from GPs and dispensing data from community pharmacists for 6 months prior to their home visit, to attempt to verify self-reported adherence. A continuous multiple-interval measure of medication availability (CMA) was calculated for three medications for each patient (cholesterol lowering, antihypertensive, and one other), by dividing the intended prescription duration (days) by the observation period (or number of days between fills) and multiplying by 100 . Scores below $80 \%$ were considered to indicate non-adherence; scores above $120 \%$ were considered overadherent. ${ }^{28}$

\section{Sample size and statistical analysis}

Based on previous reports, ${ }^{29}$ it was estimated that a sample size of 150 per group would allow detection of 15\% difference between groups in reported adherence, with $90 \%$ power, 0.05 alpha and two-tailed testing. Data were analysed using SPSS for windows (version 17). Independent-sample $t$-tests were used to examine differences between groups in parametric variables, following testing for normality of distribution; $\chi^{2}$ tests were used 


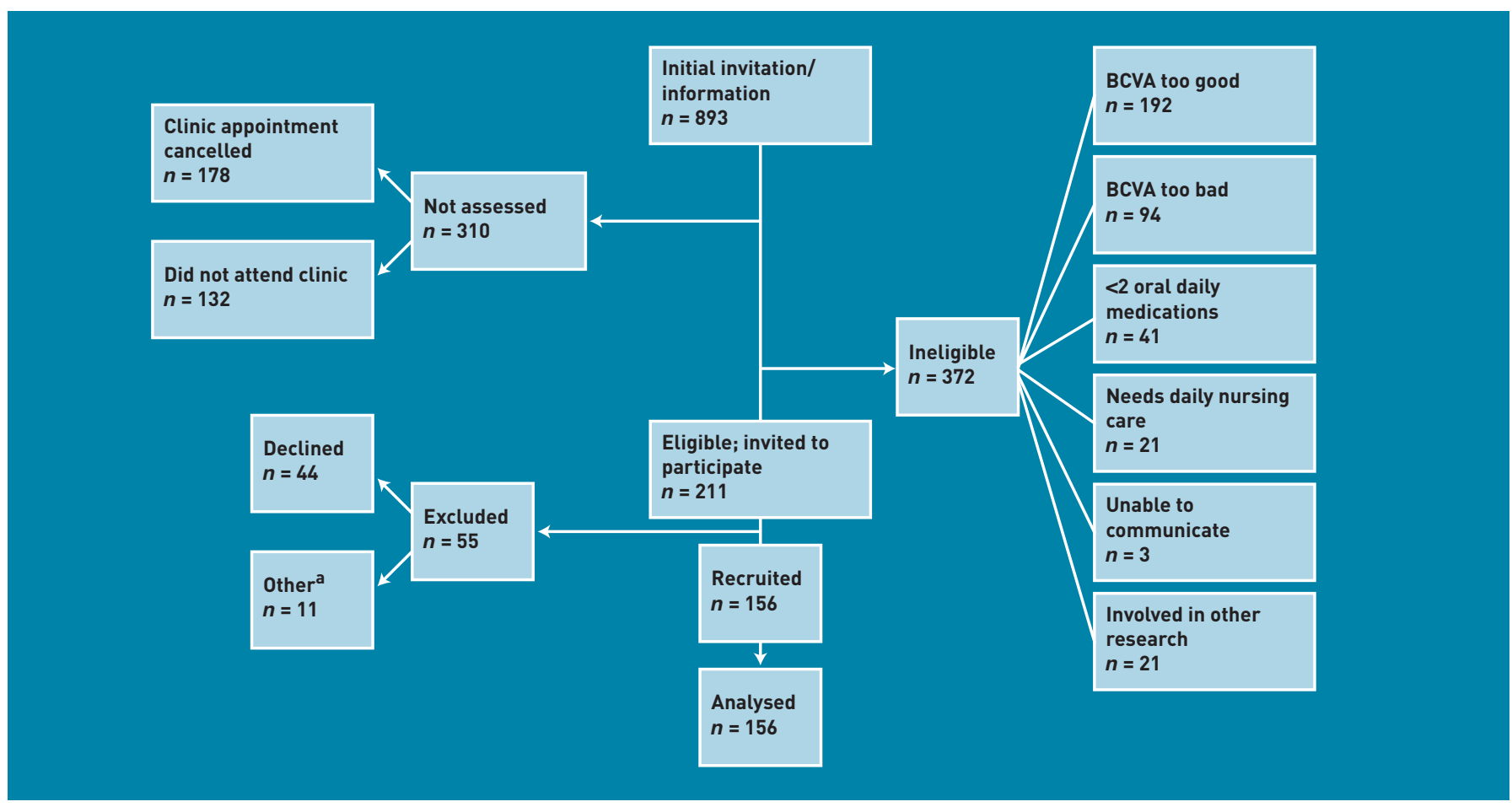

Figure 1. Flowchart for participants with visual impairment. alncludes illness and changed caring or nursing arrangements. BCVA = best corrected visual acuity.

Figure 2. Flowchart for participants in the control group. $B C V A=$ best corrected visual acuity. to compare categorical data; and differences in non-parametric data were analysed using Mann-Whitney $U$ tests. Associations between adherence scores and other variables were sought using regression analysis. Differences between groups in numbers having falls, contacts with health and social care services, and medication management were compared by calculating odds ratios (ORs).

\section{RESULTS}

Of the 893 individuals who were sent study information, for 178 their appointment was cancelled, either by the hospital or by the patient; a further 132 did not attend. Of the remainder, 372 failed to fulfil the inclusion criteria (Figure 1); 211 were eligible, 73.9\% (156/211) participated. Community optometrists identified 197 potential controls; 181 met the inclusion criteria,

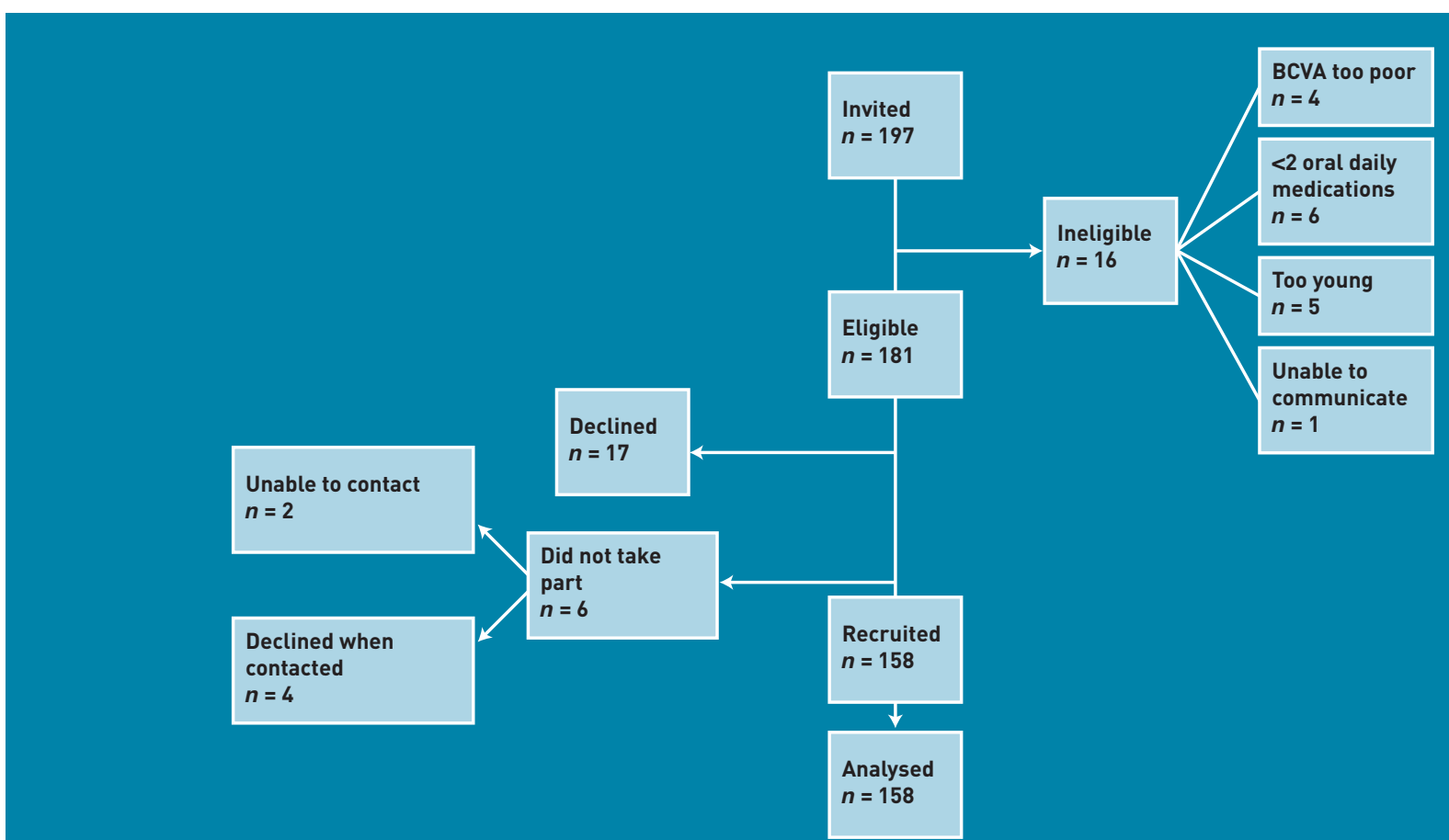


Table 1. Demographic characteristics, living arrangements, recent falls, and service use by study participants in visually impaired and control groups and the total sample

\begin{tabular}{|c|c|c|c|}
\hline Characteristic & $\begin{array}{l}\text { isually impaired } \\
\qquad(n=156)\end{array}$ & $\begin{array}{l}\text { Control } \\
\text { (n=158) }\end{array}$ & $\begin{array}{c}\text { Total } \\
(n=314)\end{array}$ \\
\hline Mean age, years (SD) ${ }^{a}$ & $81.0(7.0)$ & $77.8(6.7)$ & $79(7.0)$ \\
\hline \multicolumn{4}{|l|}{ Sex, $n(\%)$} \\
\hline Male & 56 (35.9) & $61(38.6)$ & 117 (37.3) \\
\hline Female & $100(64.1)$ & $97(61.4)$ & $197(62.7)$ \\
\hline Mean MDM'b score (SD) & 299 (198) & $301(211)$ & 300 (205) \\
\hline \multicolumn{4}{|l|}{ Living arrangements, $n(\%)$} \\
\hline Own house & 137 (87.8) & $142(89.9)$ & $279(88.9)$ \\
\hline 'Sheltered' accommodation & 19 (12.2) & $16(10.2)$ & $35(11.1)$ \\
\hline Lives alone & $77(49.4)$ & $70(44.3)$ & $147(46.8)$ \\
\hline Lives with partner & $61(39.1)$ & $72(45.6)$ & 133 (42.4) \\
\hline Lives with relative & $18(11.5)$ & $16(10.1)$ & 34 (10.8) \\
\hline Reported any fall in past 6 months, $n(\%)^{a}$ & $42(26.9)$ & $14(8.9)$ & $56(17.8)$ \\
\hline Number of GP contacts in the past 6 months, mean (SD) & $1.8(1.6)$ & $1.7(1.4)$ & $1.8(1.5)$ \\
\hline Reported any social service contact in the past 6 months, $n(\%)^{a}$ & (46.2) & $17(10.8)$ & 89 (28.3) \\
\hline
\end{tabular}

87.3\% (158) participated (Figure 2).

\section{Participant characteristics}

Participants' ages ranged from 65 to 101 years. The mean age of those with VI was higher than that of controls 181.0 versus 77.8 years, $P<0.001$ ) (Table 1); more with $\mathrm{VI}$ (33\%; $n=51)$ were aged $\geq 85$ years, compared to controls $(15 \% ; n=23)$. No

Table 2. Medication adherence questionnaire scores and medication management for visually impaired and control groups and the total sample

\begin{tabular}{|c|c|c|c|}
\hline Characteristic & $\begin{array}{l}\text { Visually impaired } \\
\qquad(n=156)\end{array}$ & $\begin{array}{c}\text { Control } \\
\text { ( } n=158)\end{array}$ & $\begin{array}{c}\text { Total } \\
\text { (n=314) }\end{array}$ \\
\hline \multicolumn{4}{|l|}{ Medication adherence } \\
\hline MARS score, mean (SD) & $23.2(2.4)$ & $23.6(2.4)$ & $23.4(2.4)$ \\
\hline Score $<18 / 25$ (non-adherent), $n(\%)$ & $10(6.4)$ & $6(3.8)$ & $16(5.0)$ \\
\hline Score $\geq 18$ and $\leq 24 / 25$ (adherent), $n(\%)$ & 81 (51.9) & 81 (51.3) & $162(51.7)$ \\
\hline Score 25/25 (perfect adherence), $n$ (\%) & 65 (41.7) & $71(44.9)$ & 136 (43.3) \\
\hline Morisky score, mean (SD) & $3.5(0.7)$ & $3.5(0.6)$ & $3.5(0.6)$ \\
\hline Score $\leq 1 / 4$ (non-adherent), $n(\%)$ & $2(1.2)$ & $1(0.6)$ & $3(1.0)$ \\
\hline Score $=2 / 4$ (medium adherence), $n(\%)$ & $7(4.5)$ & 2 (1.3) & $9(2.9)$ \\
\hline Score $=3 / 4$ (high adherence), $n(\%)$ & $65(41.7)$ & $72(45.6)$ & $137(43.6)$ \\
\hline Score $=4 / 4$ (perfect adherence), $n(\%)$ & $82(52.6)$ & 83 (52.5) & 165 (52.5) \\
\hline \multicolumn{4}{|l|}{ Medication management, $n(\%)$} \\
\hline Difficulty reading medication labels ${ }^{b}$ & $152(97.4)$ & $7(4.4)$ & $155(50.6)$ \\
\hline Uses optical aidb & $125(80.1)$ & $2(1.3)$ & $127(40.4)$ \\
\hline Difficulty distinguishing medications ${ }^{b}$ & $38(24.4)$ & 0 & $38(12.1)$ \\
\hline Difficulty opening medications & 74 (47.7) & 70 (44.3) & $144(45.9)$ \\
\hline Difficulty opening blister packs & 59 (37.8) & 55 (34.8) & $114(36.3)$ \\
\hline Requires help to manage medication ${ }^{b}$ & $45(28.8)$ & 20 (12.7) & 65 (20.7) \\
\hline Help provided by relative/friend ${ }^{b}$ & $29(18.6)$ & $16(10.1)$ & 45 (14.3) \\
\hline Uses compliance aidc & $63(40.4)$ & $57(36.1)$ & $120(38.2)$ \\
\hline Pharmacist supplies medication in compliance aida & $16(10.3)$ & $4(2.5)$ & $20(6.4)$ \\
\hline
\end{tabular}

${ }^{a} \mathrm{P}<0.05 .{ }^{b} \mathrm{P}<0.001$ : statistical testing by $\chi^{2}$; significant differences between groups. ' Compliance aid' refers to a container, divided into compartments, each of which represents a dosage time; for example, morning, noon, evening, and night, with enough compartments usually for 7 days. cognitive impairment was identified in any participant. There were no significant differences between groups in sex distribution (62.7\% female), socioeconomic status (mean MDM score 300, standard deviation $\quad[S D]=205$ ), or living arrangements $188.9 \%$ lived in their own home; $46.8 \%$ lived alone). The groups had similar educational backgrounds: the majority $(65.9 \%, n=207)$ had received only primary school education.

Falls, social services support and family physician contact

More of the group with $\mathrm{VI}(26.9 \%)$ than controls (8.9\%) reported at least one fall during the previous 6 months $1 \mathrm{OR}=3.8 ; 95 \%$ confidence interval $[\mathrm{Cl}]=2.0$ to 7.3 ; after adjusting for age, $\mathrm{OR}=3.9 ; 95 \% \mathrm{Cl}=2.0$ to 7.6) (Table 1). The groups did not differ significantly in numbers of contacts with their GP; most had consulted at least once in the previous 6 months. Of those with $\mathrm{VI}$, more $(46 \%)$ reported contact with social care services in the previous 6 months, compared to controls (10.8\%) (OR $=7.1 ; 95 \% \mathrm{Cl}=3.9$ to 12.9; age-adjusted $\mathrm{OR}=6.6 ; 95 \% \mathrm{Cl}=3.6$ to 12.1). Most individuals who had such contact received ongoing service support in dressing, personal hygiene, preparing meals, or housekeeping, but not for taking medication. Multiple regression analysis showed no association between contact with services and age or living arrangements.

Medications, adherence and management Individuals in both groups were prescribed similar numbers of medications (range $=$ 2-14; mean =5.1, SD=2.5) and types of medications, suggesting similar comorbidity in each group. Overall, 93.3\% (293/314) were prescribed cardiovascular medication, $16.6 \%$ (52/314) antidiabetic medication, 18.5\% (58/314) psychotropic medication, 32.8\% (103/314) analgesic medication, and 37.9\% (119/314) gastroprotective medication.

No differences were found between the groups in mean adherence scores. Both scales indicated that approximately half of the participants were fully adherent (MARS: 43\%; Morisky: 52\%); a minority reported poor adherence. CMA scores also indicated high levels of adherence for both groups loverall mean scores: $\mathrm{VI}=105.2$ [SD $=26.0]$, $\mathrm{C}=103.9$ [SD $=14.2]$; mean difference $=1.3$, $95 \% \mathrm{Cl}=-3.3$ to 5.9 ).

Significantly more with VI (29\%), compared to controls (13\%) (OR $=2.8[95 \%$ $\mathrm{Cl}=1.6$ to 5.0$]$; age-adjusted $\mathrm{OR}=2.6[95 \%$ $\mathrm{Cl}=1.4$ to 4.7$]$ ) relied on help to take their medication each day or to sort it into a compliance aid la container holding usually 
Table 3. Health Beliefs Questionnaire: scores ${ }^{a}$ for summary statements for visually impaired and control groups

Item

Visually impaired,

Control,

median (mean) median (mean)

Likely to become ill as a result of not taking medication as prescribed (perceived susceptibility)

Perceived serious illness resulting from not taking medication (perceived severity)

Worry when I don't take medication as prescribed (fear/anxiety)

Taking medication as prescribed prevents illness (perceived benefit)

Taking medication as prescribed is not a real burden (perceived barrier)

Confident in my ability to take medication as prescribed (self-efficacy)

Important to take care of own health (health motivation)

Most people who are important to me think it is necessary for me to take medications as prescribed

(subjective norm)

It is possible for me to take my medications as prescribed (perceived behavioural control)

aPossible scores range from 1 to $7 ; 7$ indicates full agreement with statement; 1 indicates strong disagreement with statement.

seven daily aliquots of medication, each within separate sections). Both groups used compliance aids (VI: 40\%; control: 36\%) but community pharmacists dispensed medications in these for more of the $\mathrm{VI}$ group (10\% versus $2.5 \%)(O R=4.4[95 \% \mathrm{Cl}=$ 1.4 to 13.5$]$; age-adjusted $\mathrm{OR}=3.8$ [95\% $\mathrm{Cl}=$ 1.2 to 12.0$]$ ). Compared to controls, more individuals with $\mathrm{VI}$ relied on help from relatives or friends (19\% versus 10\%). Almost all (97\%) with VI had difficulty reading medication labels, despite $80 \%$ using optical aids; $24 \%$ had difficulties distinguishing tablets, particularly in differentiating colours, compared to none of the controls. Almost half of each group had difficulties opening medications, especially blister packages. These results are summarised in Table 2.

Beliefs and quality of life

Table 3 shows summary statements for questionnaire items representing health beliefs regarding medication. To mitigate the risk of over-reporting statistical significance when running multiple tests, a significance level of 0.01 was applied. While there were several statistically significant differences between the groups, only the 'fear/anxiety' item demonstrated a difference in mean scores of more than one unit, suggesting that the effect size for other differences is small. Thus participants with VI reported a significantly higher level of anxiety about becoming ill if they did not take their medication as prescribed.

Quality of life (Table 4), measured by the SF-12 (physical and mental health components) and EQ-5D, was worse for participants with VI than controls. The DLTV questionnaire, relating to performance of tasks requiring visual acuity, showed that those with VI reported significantly greater difficulties. Table 4. Quality of life, measured by SF-12, EQ-5D and DLTV questionnaires, for visually impaired (VI) and
control (C) groups

\begin{tabular}{|c|c|c|c|c|}
\hline Quality of life measure & $\begin{array}{l}\text { Visually impaired } \\
\text { ( } n=156 \text { ), mean (SD) }\end{array}$ & $\begin{array}{c}\text { Control }(n=158), \\
\text { mean (SD) }\end{array}$ & $\begin{array}{c}\text { Difference in mean } \\
\text { scores (VI-C) }(95 \% \mathrm{Cl})\end{array}$ & $\begin{array}{l}\text { Age-adjusted difference } \\
\text { in mean scores }(95 \% \mathrm{Cl})\end{array}$ \\
\hline \multicolumn{5}{|l|}{ SF-12 } \\
\hline Mental health component & $48.2(9.6)$ & $52.7(8.0)$ & $-4.5(-6.5$ to -2.5$)$ & $-5.3(-7.2$ to -3.3$)$ \\
\hline Physical component & $39.3(11.0)$ & $43.0(10.5)$ & $-3.7(-6.1$ to -1.3$)$ & $-3.3(-7.2$ to -3.3$)$ \\
\hline \multicolumn{5}{|l|}{ EQ-5D } \\
\hline Mobility & $1.37(0.48)$ & $1.25(0.44)$ & $0.11(0.01$ to 0.21$)$ & $0.09(-0.02$ to 0.79$)$ \\
\hline Self-care & $1.15(0.40)$ & $1.05(0.22)$ & $0.10(0.03$ to 0.17$)$ & $0.08(-0.01$ to 0.06$)$ \\
\hline Ability to perform usual activities & $1.62(0.61)$ & $1.29(0.50)$ & 0.33 (0.21 to 0.45$)$ & $0.33(0.21$ to 0.46$)$ \\
\hline Pain & $1.31(0.49)$ & $1.18(0.40)$ & 0.13 (0.03 to 0.23$)$ & $0.14(0.04$ to 0.24$)$ \\
\hline Anxiety & $1.19(0.39)$ & $1.09(0.31)$ & 0.10 (0.02 to 0.18$)$ & $0.13(0.05$ to 0.21$)$ \\
\hline \multicolumn{5}{|l|}{$\overline{\text { DLTV }}$} \\
\hline DIM 1a & $26.5(17.1)$ & $97.3(3.4)$ & $-70.8(-73.6$ to -68.1$)$ & \\
\hline DIM $2^{b}$ & $66.3(22.9)$ & 100 (0.3) & $-36.7(-40.3$ to -33.1$)$ & \\
\hline
\end{tabular}

DLTV = Daily Living Tasks associated with Vision. SD = standard deviation. SF = Short Form. EQ = EuroQol. aDIM 1: dimension 1, relates to tasks that require optimal visual acuity (for example, watching TV, distinguishing a person's features across the street, reading normal-sized newspaper print). ${ }^{b} D I M$ 2: dimension 2, relates to tasks less dependent on optimal visual acuity (for example, distinguishing a person's features at arm's length, reading newspaper headlines). 


\section{DISCUSSION}

\section{Summary}

These findings indicate that, while older people with and without $\mathrm{VI}$ achieve similar levels of medication adherence, those with $\mathrm{VI}$ require and receive significantly more support in medication self-management: they were more than twice as likely to require help and four times as likely to receive support from a community pharmacist. Almost 30\% of participants with VI required help daily in taking their prescribed medication: despite using optical aids, almost all had difficulty reading information. Compared to their peers, significantly more with $\mathrm{VI}$ had difficulty distinguishing between medications but almost half of both groups had difficulties opening packaging. This report provides novel information about people with defined levels of $\mathrm{VI}$, and indicates that the impact of $\mathrm{VI}$ on medication self-management should be considered when planning health and social care.

The study was funded by The Big Lottery Fund.

\section{Ethical approval}

The Office of Research Ethics Committees (Northern Ireland) approved the study (Reference Number: 06/NIR01/140).

\section{Provenance}

Freely submitted; externally peer reviewed.

\section{Competing interests}

The authors have declared no competing interests.

\section{Acknowldegments}

The authors wish to thank the Royal National Institute for the Blind (RNIB) for their support and oversight of the study and The Blind Centre for Northern Ireland for their initial involvement in it; optometrists in low-vision clinics and in the community for recruiting participants; the $\mathrm{NI}$ Clinical Research Network (Primary Care and Vision) for facilitating data collection; and participants' family physicians and pharmacists, for providing access to prescribing data. We also thank Ms Pat Hart (Consultant Ophthalmologist, Royal Group of Hospitals, Belfast), Dr Drew Gilliland ISenior Lecturer, General Practice, Queen's University, Belfast), Mr David Bickerstaff (Belfast Health and Social Care Trust), Mr David Mann (RBNI), and Mrs Karen Toogood (RBNI) for their valued contributions to the Study Steering Committee.

\section{Discuss this article}

Contribute and read comments about this article on the Discussion Forum: http://www.rcgp.org.uk/bjgp-discuss while similar adherence behaviour was reported by both groups, those with VI needed significantly more assistance.

\section{Comparison with existing literature}

There are few reports of levels of adherence to long-term therapies in general practice. This work adds to a previous report of older people with a range of self-reported vision impairments: ${ }^{33}$ its finding of a smaller proportion (10.8\%) reporting difficulty managing medication may be because it included people with minor visual deficits, potentially corrected by spectacles. The study has defined participants' visual acuity and described the problems experienced and help received, thus informing future strategies for medication self-management that should improve healthcare access for people with VI. ${ }^{34}$

Use of social care services was greater among those with VI. However, individuals mostly relied on informal social and family networks for help in managing medication. Older Australians have reported increased reliance on community and family support services as their VI increased. ${ }^{30} \mathrm{VI}$ adversely influences people's ability to care for themselves and their dependents. ${ }^{35}$ As society ages and VI increases in prevalence, sources of informal support for those needing help will become less and a need for other resources will increase. Multimodal interventions are likely to be required: recognising patients' problems is the initial step in relevant intervention design. ${ }^{36}$

Major problems relating to pharmaceutical packaging have been reported. ${ }^{37}$ Lack of standardisation in packaging can cause confusion, particularly for older people, and is a barrier to their self-management. Several participants' 'coping strategies', including memorising medications by touch, shape, or colour, were upset when, with generic prescribing, the size, shape, and colour of tablets and/or packaging varied for prescriptions dispensed on different occasions. There is a need for pharmaceutical companies and policy-makers to engage more with patients, to determine cost-effective ways of minimising problems due to different generic preparations of the same medicine, and to design more accessible packaging (while recognising child safety issues).

Health beliefs are significant predictors of medication adherence. ${ }^{13}$ The study participants with $\mathrm{VI}$ reported fear of the consequences of not taking medication as prescribed, a feeling that may contribute to their poorer quality of life. Recognising their 
need for support in medication management is important.

\section{Implications for research and practice}

This study was set in the context of the UK $\mathrm{NHS}$, within which the potential influences of costs of treatment and services on medication adherence are removed, as these are free at the point of care. However, the findings indicate an insidious rising tide of need for help in medication selfmanagement, as the numbers of older people with $\mathrm{VI}$ increase. Healthcare professionals should ask patients about their vision, ${ }^{34}$ and check that they have sufficient support in opening packaging, distinguishing tablets, measuring liquids, or using eye drops or injections. Practical help may include providing more accessible information through large-print labels different textures and shapes of containers, 38 electronic devices with pre-recorded voice messages ('talking labels'), devices for scanning labels and converting to audio format ('pen-friends'), syringe-filling aids, and 'pillboxes' with medication packed in daily quantities. Clinicians' and pharmacists' awareness of solutions to patients' problems should prompt them to inform policymakers and pharmaceutical companies regarding ways to improve their health care, recognising the associated cost implications for commissioning of future services. Further research, exploring how best to address their needs, is warranted, to avoid potential adverse health consequences from non-adherence to prescribed medication, and to inform strategies for cost-effective support programmes. 


\section{REFERENCES}

1. Owen CG, Fletcher AE, Donoghue M, Rudnicka AR. How big is the burden of vision loss caused by age related macular degeneration in the United Kingdom? Br J Ophthalmol 2003; 87(3): 312-317.

2. Mangione CM, Gutierrez PR, Lowe G, et al. Influence of age related maculopathy on visual functioning and health related quality of life. Am $J$ Ophthalmol 1999; 128(1): 45-53.

3. Williams RA, Brody BL, Thomas RG, et al. The psychological impact of macular degeneration. Arch Ophthalmol 1998; 116(4): 514-520.

4. Ivers RQ, Cumming RG, Mitchell $P$, Attebo K. Visual impairment and falls in older adults: The Blue Mountain Study. J Am Geriatr Soc 1998; 46(1): 58-64.

5. Rovner BW, Ganguli M. Depression and disability associated with impaired vision: the MoVies Project. J Am Geriatr Soc 1998; 46(5): 617-619.

6. Waern M, Rubenowitz E, Runeson B, et al. Burden of illness and suicide in elderly people: case-control study. BMJ 2002; 324(7350): 1355-1357.

7. Lin MY, Gutierrez PR, Stone KL, et al. Vision impairment and combined vision and hearing impairment predict cognitive and functional decline in older women. J Am Geriatr Soc 2004; 52(12): 1996-2002.

8. Bayliss EA, Ellis JL, Steiner JF. Barriers to self-management and quality-oflife outcomes in seniors with multimorbidities. Ann Fam Med 2007; 5(5): 395-402.

9. Bane C, Hughes CM, McElnay JC. The impact of depressive symptoms and psychosocial factors on medication adherence in cardiovascular disease. Patient Educ Couns 2006; 60(2): 187-193.

10. Gellad WF, Grenard JL, Marcum ZA. A systematic review of barriers to medication adherence in the elderly: looking beyond cost and regimen complexity. Am J Geriatr Pharmacother 2011; 9(1): 11-23.

11. Gu Q, Dillon CF, Burt VL. Prescription drug use continues to increase: US prescription drug data for 2007-2008. NCHS Data Brief 2010; (42): 1-8.

12. National Audit Office. Prescribing costs in primary care. Report by the Comptroller and Auditor General. London: HMSO, 2007.

13. World Health Organization. Adherence to long-term therapies: evidence for action. Geneva: WHO, 2011.

http://www.who.int/chp/knowledge/publications/adherence_report/en/index.ht $\mathrm{ml}$ laccessed 2 Jul 2012).

14. Ruscin JM, Semia TP. Assessment of medication management skills in older outpatients. Ann Pharmacother 1996; 30(10): 1038-1088.

15. Karamanidou C, Clatworthy J, Weinman J, Horne R. A systematic review of the prevalence and determinants of nonadherence to phosphate binding medication in patients with end stage renal disease. BMC Nephrol 2008; 9: 2 .

16. Kerse N, Buetow S, Mainous AG, et al. Physician-patient relationship and medication compliance: a primary care investigation. Ann Fam Med 2004; 2(5): 455-461.

17. Bailey IL, Lovie JE. New design principles for visual acuity letter charts. Am J Optom Physiol Opt 1976; 53(11): 740-745

18. H54. Blindness and low vision. In: World Health Organization. International statistical classification of diseases and related health problems. 10th revision. Geneva: WHO, 2003. http://www.who.int/classifications/icd/en/ laccessed 2 Jul 2012).

19. Pattie AH, Gilleard CJ. A brief psychogeriatric assessment schedule. Validation against psychiatric diagnosis and discharge from hospital. Br J Psychiatry
1975; 127: 489-493.

20. Northern Ireland Statistics and Research Agency. www.nisra.gov.uk/ laccessed 2 Jul 2012).

21. Horne R. Non-adherence to medication: causes and implications for care. In: Gard P (ed.). A behavioural approach to pharmacy practice. Oxford: Blackwell, 2001: 111-130.

22. Morisky DE, Green LW, Levine DM. Concurrent and predictive validity of a selfreported measure of medication adherence. Med Care 1986; 24(1): 67-74.

23. Becker MH. Health belief model. The health belief model and personal health behaviour. Health Educ Monogr 1974; 2: 324-473.

24. Ajzen I. Theory of planned behaviour. From intentions to actions: a theory of planned behaviour. In: Kuhl J, Beckman J (eds.). Action-control: from cognition to behaviour. Heidelberg: Springer, 1985: 11-39.

25. Ware J Jr, Kosinski M, Keller SD. A 12-item short-form health survey: construction of scales and preliminary tests of reliability and validity. Med Care 1996; 34(3): 220-223.

26. Kind P. The EuroQol instrument: an index of health-related quality of life. In Spilker B (ed.). Quality of life and pharmacoeconomics in clinical trials (2nd edn). Philadelphia, PA: Lippincott-Raven Publishers, 199: 191-202.

27. Hart PM, Chakravarthy U, Stevenson MR, Jamison JQ. A vision specific functional index for use in patients with age related macular degeneration. $\mathrm{Br}$ J Ophthalmol 1999; 83(10): 1115-1120

28. Steiner JF, Prochazka AV. The assessment of refill compliance using pharmacy records: methods, validity and applications. J Clin Epidemiol 1997; 50(1): 105-116.

29. Roth MT, Ivey JL. Self-reported medication use in community-residing older adults: a pilot study. Am J Geriatr Pharmacother 2005; 3(3): 196-204.

30. Wang JJ, Mitchell P, Smith W, et al. Impact of visual impairment on the use of community support services by elderly persons: The Blue Mountain Eye Study. Invest Ophthalmol Vis Sci 1999; 40(1): 12-19.

31. Coleman AL, Stone $K$, Ewing SK, et al. Higher risk of multiple falls among elderly women who lose visual acuity. Ophthalmology 2004; 111(5): 857-862.

32. Varma R, Wu J, Chong K, Azen SP, Hays RD. Impact of severity and bilaterality of visual impairment on health related quality of life. Ophthalmology 2006: 113(10): 1846-1853.

33. Crews JE, Campbell VA. Vision Impairment and hearing loss among community-dwelling older Americans: implications for health and functioning. Am J Public Health 2004; 94(5): 823-829.

34. Cupples ME, Hart PM, Johnston A, Jackson AJ. Improving healthcare access for people with visual impairment and blindness. BMJ 2012; 344: e542.

35. Stevenson MR, Hart PM, Montgomery A-M, et al. Reduced vision in older adults with age related macular degeneration interferes with ability to care for self and impairs role as carer. Br J Ophthalmol 2004; 88(9): 1125-1130.

36. Ho PM, Bryson CL, Rumsfeld JS. Medication adherence: its importance in cardiovascular outcomes. Circulation 2009; 119(23): 3028-3035.

37. Rigby M. Pharmaceutical packaging can induce confusion. BMJ 2002; 324(7338): 679

38. The American Society of Consultant Pharmacists Foundation, and the American Foundation for the Blind. Guidelines for prescription labelling and consumer medication information for persons with vision loss. http://www.afb.org/section.aspx?FolderlD=3\&SectionID=3\&TopicID=329\&Docu mentID=4064 (accessed 9 Ju1 2012). 